\title{
Peripheral B-Lymphocyte
}

National Cancer Institute

\section{Source}

National Cancer Institute. Peripheral B-Lymphocyte. NCI Thesaurus. Code C38330.

A mature B-lymphocyte outside the bone marrow. It may be in the general circulation or in lymphatic tissue. 